Arteterapia. Papeles de arteterapia y educación para inclusión social ISSN-e 1988-8309

\title{
Educación comunitaria a través de las artes: hacia una etnografía visual del graffiti y del arte urbano con jóvenes
}

\author{
Pere Grané Feliu ${ }^{1}$; Montserrat Rifà Valls²; Miquel Àngel Essomba Gelabert ${ }^{3}$
}

Recibido: 27 de abril de 2017 / Aceptado: 06 de julio de 2017

Resumen. Este artículo se fundamenta en la hipótesis de que el graffiti y el arte urbano pueden promover procesos de educación comunitaria a través de las artes. A pesar de que existe literatura especializada en el ámbito del graffiti y el arte urbano, resulta difícil encontrar investigaciones que lo evalúen desde una perspectiva educativa. Mediante la etnografía visual, se presenta el análisis de tres casos desarrollados con jóvenes en los barrios del Carmel (Barcelona) y Collblanc (L'Hospitalet de Llobregat) en 2014, 2015 y 2016. Concretamente, el análisis se centra en la participación, la relación del proceso con la comunidad y las relaciones de poder que se dan en este tipo de acciones educativas a través de las artes.

Palabras clave: Educación comunitaria; etnografía visual; jóvenes; graffiti; arte urbano.

\section{[en] Community education through arts: towards a visual ethnography of graffiti and street art with young people}

\begin{abstract}
This article is based on the hypothesis that graffiti and street art can promote community education processes through arts. Although there is specialized literature in this field, it is difficult to find research that evaluates graffiti and street art from an educational perspective. Through visual ethnography, three case studies are presented in which youth people participated, developed in Carmel (Barcelona) as well as Collblanc (L'Hospitalet de Llobregat) neighbourhoods' in 2014, 2015 and 2016. In particular, the analysis is focused on participation, the relation between processes and communities and the influence of power relationships in this sort of educational actions through arts.
\end{abstract}

Key words: Community education; visual ethnography; youth people; graffiti; street art.

Sumario. 1. Introducción. 2. Enmarcando el graffiti y el arte urbano en la educación comunitaria a través de las artes. 3. La etnografía visual como método de análisis en educación a través de las artes. 4. «Participación», «comunidad» y «relaciones de poder» en acciones educativas mediante graffiti y arte urbano. 5. Factores que intervienen en procesos de educación comunitaria a través de las artes mediante graffiti y arte urbano. 6. Reflexiones finales. 7. Referencias bibliográficas.

1 Departamento de Pedagogía Aplicada. Universidad Autónoma de Barcelona Email: pere.grane@uab.cat

2 Departamento de Didáctica de la Expresión Musical, Plástica y Corporal. Universidad Autónoma de Barcelona Email: montserrat.rifa@uab.cat

3 Departamento de Pedagogía Aplicada. Universidad Autónoma de Barcelona

Email:miquelangel.essomba@uab.cat 
Cómo citar: Grané Feliú, P.; Rifà Valls, N.; Essomba Gelabert, M.A. (2017). Educación comunitaria a través de las artes: hacia una etnografía visual del graffiti y del arte urbano con jóvenes, en Arteterapia. Papeles de arteterapia y educación para inclusión social 12, 61-78.

\section{Introducción}

Este análisis constituye el proceso inicial de una investigación-acción, donde se ha construido un proyecto de educación comunitaria con diversos agentes ${ }^{4}$. Durante la participación en las acciones educativas de este proceso y en el análisis posterior de los datos, la etnografía visual ha tenido un papel central. Además, esta investigación incorpora una perspectiva de género de forma transversal en el análisis e incluye referentes teóricos y metodológicos feministas. En esta ocasión, analizaré tres casos que he seleccionado por su singularidad, no porque sean representativos de todas las actividades educativas relacionadas con el graffiti o arte urbano, sino porque de su análisis se derivan distintos factores que hay que tomar en consideración. Dichas experiencias se realizaron en el barrio del Carmel (Barcelona) y Collblanc (L'Hospitalet de Llobregat) y sucedieron a lo largo de tres años (2014, 2015 y 2016). A continuación, se presentan las conceptualizaciones teóricas y metodológicas del estudio, así como los ensayos visuales y las reflexiones finales.

\section{Enmarcando el graffiti y el arte urbano en la educación comunitaria a través de las artes}

El desarrollo neoliberal está marcado por la desigualdad y el empobrecimiento de las clases más precarizadas, lo cual golpea las relaciones sociales y las comunidades. Diversas contribuciones sociológicas han abordado cómo las dinámicas capitalistas, basadas en la maximización perpetua de beneficios, afectan a las ciudades (Lefebvre, 1969; Harvey, 1973 y Castells, 1977); y cómo éstas limitan el derecho a la participación y a la re-apropiación, mientras reproducen discriminaciones y exclusiones en el espacio público (Rodó-de-Zárate, 2016). En contraposición a estas dinámicas, han surgido y se han reactivado modos de vida, valores, procesos, vínculos, redes y proyectos sociales que salen de la lógica individualista, competitiva y fragmentadora del capitalismo. Estas propuestas tienen en común que mediante la "recomposición de los tejidos sociales, la emergencia de nuevas sociabilidades, asociaciones y movimientos sociales, así como de nuevos modos de entender lo público y la democracia, están reivindicando lo comunitario" (Torres, 2002: 34).

En este contexto, diversos autores justifican la necesidad de que lo local y la comunidad sean el marco de referencia en educación porque "es el medio idóneo

$4 \quad$ Este trabajo es fruto de la tesis “Jóvenes, arte urbano y educación comunitaria: investigación-acción y etnografía visual en el distrito Collblanc - La Torrassa (L'Hospitalet de Llobregat)”, realizada en el marco del Programa de Doctorado en Educación de la Universitat Autònoma de Barcelona (UAB), con el apoyo de la Secretaria d'Universitats $i$ Recerca del Departament d'Economia i Coneixement de la Generalitat de Catalunya y el Fondo Social Europeo. 
para trabajar cuestiones como la recuperación del espacio público, la identidad o la cohesión social" (Mayugo, Pérez y Ricart, 2004: 34) . La comunidad construye un espacio de proximidad y encuentro ciudadano que permite tener referentes y sentirse identificado; un espacio de corresponsabilidad imposible de ubicar en marcos más amplios (Civís y Riera, 2007). Teniendo en cuenta esto, la educación comunitaria considera la comunidad como agente educador, sujeto educando y realidad de partida de la acción educativa. Concretamente, la educación comunitaria es el fruto de "iniciativas en las que participan de forma estable, aunque sea con desigual intensidad, los distintos agentes socioeducativos de un territorio" (Civís y Longás, 2015). Esta concepción está vinculada al trabajo en red, la colaboración entre agentes educativos y la implicación de la ciudadanía como un esfuerzo colectivo para dar respuestas integrales. A diferencia de otras definiciones que conciben la educación dada a la comunidad desde las escuelas o el trabajo comunitario, la educación comunitaria plantea la realización de procesos de voluntad transformadora que parten de las necesidades de la propia comunidad, donde la participación, el empoderamiento y la autogestión pasan a ser fundamentales.

La hipótesis de partida en este artículo considera que el graffiti y el arte urbano pueden servir para promover procesos de educación comunitaria a través de las artes. Esta «educación comunitaria a través de las artes» mantiene una estrecha relación con determinadas concepciones del «arte comunitario»:

El término arte comunitario se asocia a un tipo de prácticas que buscan una implicación con el contexto social, que persiguen, por encima de unos logros estéticos, un beneficio o mejora social y sobre todo, que favorecen la colaboración y la participación de las comunidades implicadas en la realización de la obra (Palacios, 2009: 199).

La educación comunitaria a través de las artes, mediante el uso de prácticas artísticas participativas, "se convierte en una forma de creatividad al servicio de la comunidad, trabajando para la conformación de vínculos y espacios de encuentro creativo" (López, 2015). Por lo tanto, las acciones educativas de carácter comunitario relacionadas con prácticas artísticas participativas guardan una estrecha relación con el arte comunitario. Desde la perspectiva de género, la educación comunitaria mediante las artes abre la puerta a cambiar de perspectiva y fomentar el empoderamiento de la comunidad. Concretamente, en la implicación de mujeres en el futuro de sus barrios y en promover una mayor sensación por parte de las mujeres de la comunidad de ser creativas, con confianza en sí mismas y con capacidad de decisión (López, 2015).

Tener una idea del camino andado en este ámbito es necesario para que propuestas actuales con inquietudes similares "no tengan necesidad de volver atrás, a los comienzos, para reinventar la rueda" (Harding, 2006, citado por Palacios, 2009: 209). Teniendo en cuenta esto, uno de los ejemplos más significativos de arte comunitario llevado a cabo en el espacio público en colaboración entre artistas y comunidades locales es el muralismo indígena y chicana/o de los sesenta y los setenta en California. Según Latorre (2008), a través de los murales comunitarios los chicanas/os encontraron una herramienta única para reivindicar su agencia desde el margen, cuya

Traducción propia. 
auto-representación se convertía en una forma de descolonización. La naturaleza colectiva del muralismo comunitario chicano/a implicaba un proceso de transformación para los artistas y las comunidades, quienes experimentaban un proceso radical de concientización, en términos de Paulo Freire, en el cual las personas tomaban conciencia de su opresión pero también de su poder de transformación. Así, los murales tenían un rol educativo para una población que culturalmente y políticamente estaba excluida. Sin embargo, hay poca investigación sobre el papel de los murales como experiencias educativas alternativas (Latorre, 2008). El muralismo comunitario, el graffiti y el arte urbano, en esencia, tienen elementos compartidos, como por ejemplo la importancia del espacio en las intervenciones artísticas. Tanto para el graffiti como el muralismo comunitario, los movimientos por los derechos civiles de la década de los sesenta en EEUU y el mayo del 68 tuvieron una influencia importante (Calogirou, 2010). Ambos se convirtieron en formas artísticas que funcionaron como una reacción de rebelión en los entornos urbanos (Latorre, 2008). El muralismo, el graffiti y, posteriormente, el arte urbano, son corrientes culturalmente independientes pero que se influencian mutuamente.

A grandes rasgos, el graffiti es una expresión creativa urbana compleja que se da dentro de lo que se llama graffiti subculture. La subculturas del graffiti se caracterizan por una libertad estructurada de sus miembros, quienes responden a normas, roles y estructuras autogeneradas (Macdonald, 2001), donde la competitividad es un rasgo fundamental (Abarca, 2010; Wacławek, 2011; Avramidis y Dakopoulou, 2012). Otro elemento característico del graffiti es que se trata de una forma de participación visual en el espacio público, sea de forma autorizada o no. En términos visuales, uno de los elementos que define el graffiti es el uso de códigos cerrados: técnica, vocabulario gráfico, formato y estilo. Actualmente, algunos autores sostienen que las subculturas del graffiti ya no se pueden concebir como subculturas juveniles, ilegales y monolíticas (McAuliffe, 2013). Aparte de estas cuestiones, en el graffiti, como en otras subculturas urbanas (skateboarding, parkour, etc.), se dan sesgos de género importantes que condicionan la participación de personas que no se identifican con la masculinidad hegemónica (Connell y Messerschmidt, 2005). El graffiti, junto con otras tradiciones artísticas occidentales (como el punk, el skateboarding y la contrapublicidad), dio lugar a lo que se conoce como «arte urbano» ${ }^{6}$ o post-graffiti. A diferencia del graffiti, el arte urbano no constituye una verdadera subcultura, sino un movimiento cultural de código abierto y contenido explícito, también político, que propaga su obra a través de técnicas diversas con el fin de establecer una relación con las personas espectadoras. Se trata de una "actuación artística que tiene lugar en el espacio público por iniciativa exclusiva del artista y de forma libre de control externo alguno, que responde a intereses no comerciales, y cuyos frutos físicos, cuando los hay, son abandonados a su suerte" (Abarca, 2010: 39). Mediante la ocupación de lugares físicos en el paisaje urbano y la involucración de la gente en la experiencia del arte, el arte urbano contribuye a la creación de espacios en las ciudades (Wacławek, 2011).

Otro rasgo común que comparten el graffiti, el arte urbano y el muralismo comunitario es la existencia de un sesgo androcéntrico. Esto es lo que motivó a feministas

El término «arte urbano» podría incluir cualquier creación artística (música, teatro, circo, escultura, danza, pintura, etc.) realizada en un entorno urbano. Sin embargo, en la literatura especializada publicada en español este concepto se utilizada para hacer referencia a lo que en inglés se conoce como street art. 
chicanas, como Judy Baca, Juana Alicia y Yreina Cervántez, a constituir el colectivo Mujeres Muralistas para problematizar la ortodoxia masculina y a artistas de arte urbano a crear iniciativas de solidaridad entre mujeres, como por ejemplo Few and Far (Recinos, 2015) o la revista Cat Fight (Adeline, s.f). Las razones que explican este sesgo son diversas. Por un lado, están relacionadas con el hecho de que "la ciudad pues, sus exteriores, quedan construidos como espacios masculinos, espacios para hombres y las actividades designadas como masculinas" (López, 2015: 226). Según Rodó-de-Zárate (2013), en las sociedades heteropatriarcales el género, la visibilidad del cuerpo sexuado y la expresión de la sexualidad tienen unas implicaciones que dan lugar al miedo, el peligro y el riesgo como controladores del acceso al espacio público. Por otro lado, también está asociado a dinámicas de funcionamiento basadas en la masculinidad hegemónica. Por ejemplo, en el caso de las subculturas del graffiti la investigación realizada por Macdonald (2001) analiza los mecanismos de cosificación, paternalismo y estigmatización que favorecen que haya un funcionamiento orientado a la afirmación de la masculinidad. Finalmente, estos sesgos tienen que ver con el hecho de que se trata de fenómenos transnacionales y transhistóricos que llevan una carga machista importante a través del tiempo y el espacio (Latorre, 2008).

\section{La etnografía visual como método de análisis en educación a través de las artes}

Los documentos visuales ofrecen la posibilidad de que cada persona se imagine y se ubique físicamente y emocionalmente en el mundo del otro. La etnografía visual explora modos de conocimiento que a menudo quedan ocultos, pero que forman parte de la rutina de la población que participa en la investigación. No se limita a usar métodos visuales para documentar, sino que también está comprometida con la producción y representación de conocimiento (Pink, 2006). Además, algunas etnografías participativas realizan intervenciones que se basan en el conocimiento de las personas que colaboran en la investigación, tratando de adoptar un posicionamiento basado en el «estar con», en lugar del «saber sobre». Este tipo de métodos ofrece la posibilidad de impactar en la comunidad mediante el uso de nuevas formas de autoconciencia y comprensión por parte de las personas que participan en la investigación (Pink, 2014). Lo importante no es sólo el producto del proyecto aplicado, sino el proceso a través del cual se hace. Por otro lado, la etnografía visual presenta un componente divulgativo mayor, a la vez que permite generar diversos espacios de representación y diálogo. Por ejemplo, a menudo este tipo de investigaciones producen documentos visuales y audiovisuales que facilitan el diálogo intercultural. El énfasis en los métodos visuales ofrece la posibilidad de promover investigaciones etnográficas innovadoras alejadas de las más clásicas de la academia (Pink, 2011). Esto permite hacer sentir experiencias, voces y sentimientos que frecuentemente son invisibles o difíciles de verbalizar. Sin embargo, tal como remarcan las contribuciones feministas, las personas que utilizamos estos métodos continuamos estando situadas y, por lo tanto, los respectivos análisis están parcialmente limitados por nuestras posiciones (de clase, cultura, posición institucional, género, etnia, entre otros) (Zavos y Biglia, 2009). Además, las aportaciones feministas ponen de manifiesto el 
hecho de que los métodos etnográficos comportan una intrusión e intervención en la vida de las personas participantes y su sistema de relaciones, porque el análisis y la documentación de sus experiencias supone objetivarlas y exponerlas.

Concretamente, el método etnográfico visual empleado en esta investigación se ha basado en la fotografía, que es pertinente tanto en el ámbito del graffiti y el arte urbano como en el educativo. En el caso del graffiti, la fotografía ha tenido un papel fundamental dado el carácter efímero de las intervenciones artísticas (Novak, 2015). En esta dirección, el trabajo de fotoperiodistas históricas, como por ejemplo Martha Cooper, ha contribuido mediante la fotografía y los documentos audiovisuales a que el graffiti se haya extendido por todo el mundo, porque permiten prolongar la presencia de las intervenciones artísticas más allá de su emplazamiento físico (McAuliffe, 2012). Con la aparición de internet, el uso de la fotografía y el vídeo ha crecido exponencialmente. Actualmente, el graffiti y el arte urbano se desarrollan y evolucionan a través de la fotografía digital y su difusión en las redes sociales. Por otro lado, la fotografía ofrece la posibilidad de explicar e interpretar visualmente problemáticas que pertenecen al ámbito educativo. En las investigaciones educativas basadas en la fotografía las imágenes son los elementos más importantes y decisivos de la investigación: "Permiten definir el problema, describir el contexto, ofrecen e interpretan información, argumentan un conjunto de hallazgos y rebelan conclusiones (las cuales, a la vez, pueden ser también fotografías)" (Marín y Roldán, 2010: 9) ${ }^{7}$. Para Marín y Roldán (2010), las investigaciones en educación que se basan en la fotografía deben organizar las fotografías en series que presenten un argumento visual, preferiblemente mediante ensayo o discurso fotográfico. Concretamente, un ensayo fotográfico se utiliza para comprender un tema mediante la composición de imágenes en un todo coherente, en el cual cada imagen tiene una interrelación con las demás. Este método es especialmente relevante para aquellas investigaciones cuyos participantes son jóvenes, ya que, de acuerdo con Marcellan-Baraze, Calvelhe, Agirre y Arriaga (2012), la fotografía es el medio de producciones visuales más extendido entre la juventud por ser el más accesible. En consecuencia, la etnografía visual ofrece la posibilidad de que la población participante tenga un papel activo y cierto control de las técnicas utilizadas en la investigación.

De forma coherente con todo la anterior, en esta investigación la etnografía visual no se ha limitado a la tarea de documentación, sino que me ha permitido una relación con la producción y representación visual del conocimiento diferente en cada caso (Pink, 2006). En la primera observación (caso A), facilitó la exploración y representación de las relaciones de las personas participantes con la acción educativa. En el segundo caso (caso B), permitió hacer una evaluación de la acción educativa mediante la reflexión posterior de los cambios visuales que habían sufrido las intervenciones artísticas. En el último (caso C), la etnografía visual facilitó que las personas participantes tomaran parte en la detección de necesidades y posterior deliberación. Esto favoreció que la acción educativa se centrara en las imágenes de los espacios públicos más significativos de su barrio y sus vivencias en éstos. Además, este método ha contribuido a la difusión de las acciones en las redes sociales y el posterior debate con la comunidad.

En el proceso de esta investigación coinciden múltiples miradas, de acuerdo con las diversas trayectorias, experiencias y disciplinas de referencia de los investiga-

Traducción propia. 
dores: sociología, artes visuales y educación comunitaria. Además, mi participación como doctorando en el trabajo de campo, la llevé a cabo desde mi triple faceta como investigador, educador y artista de graffiti. Esta participación, junto con el diálogo permanente con los directores de tesis, permitió identificar tres ejes de análisis que han sido claves para profundizar en la hipótesis planteada: (1) la participación de las personas involucradas; (2) la relación entre el proceso y la comunidad; y (3) las relaciones de poder existentes entre los agentes de la comunidad. Los fragmentos de la etnografía visual no se presentan de forma secuencial, sino que han sido compuestos de acuerdo con los ejes mencionados. Mediante un análisis transversal se pretende evitar la jerarquización de los casos expuestos. Según McNiff (1988), la investigación-acción tiene que ser un proceso espontáneo, que se auto-recrea; un proceso de observación, descripción, planificación, acción, reflexión, avaluación no sea necesariamente secuencial. Durante la etnografía visual participativa, garantizar y preservar la confidencialidad de los participantes (tanto de los jóvenes como de los educadores) fue clave para el desarrollo del proyecto, así como la negociación sobre el consentimiento para la publicación de las evidencias. ${ }^{8}$ Por último, se incluye una tabla resumen de los casos que sintetiza el resultado de la observación participante.

\section{4. «Participación», «comunidad» $\mathrm{y}$ «relaciones de poder» en acciones educativas mediante graffiti y arte urbano}

En general, existe una tendencia a presentar la «comunidad» desde imágenes idealizadas, donde se invisibilizan las diferencias, las tensiones y los conflictos de la vida social y se asume esta como una realidad transparente e incuestionable (Torres, 2002). Esto facilita que la descripción de proyectos comunitarios se convierta en un instrumento enmascarador de conflictos, puesto que se limita a celebrar los aspectos positivos, dejando de lado los problemas y contradicciones de las situaciones tratadas (Sánchez de Serdio, 2008). A continuación, se incluyen los ensayos visuales y análisis realizados alrededor de los tres ejes que, fruto del proceso de observación y participación, he identificado relevantes para analizar este tipo de procesos de educación comunitaria a través de las artes. Cada ensayo fotográfico incluye fotografías de los diferentes casos y un breve fragmento informativo sobre la autoría de éstas. El caso A, se corresponde con una intervención artística realizada en el barrio del Carmel (Barcelona) en 2014. El caso B, muestra una intervención artística realizada en el barrio de Collblanc (L'Hospitalet de Llobregat) en 2015. El caso C, se corresponde con una intervención artística realizada en el mismo barrio el año siguiente. Finalmente, en cada uno de éstos he explicitado el papel del investigador y el de las personas participantes para que las otras personas tengan más elementos para comprender y criticar los análisis (Biglia, 2007).

La Universitat Autonònoma de Barcelona tiene un Código de buenas prácticas que subscriben tanto estudiantes de doctorados como directores de tesis: http:/www.uab.cat/doc/codigo-buenas-practicas-es. 
La participación de las personas involucradas

Figura 1c
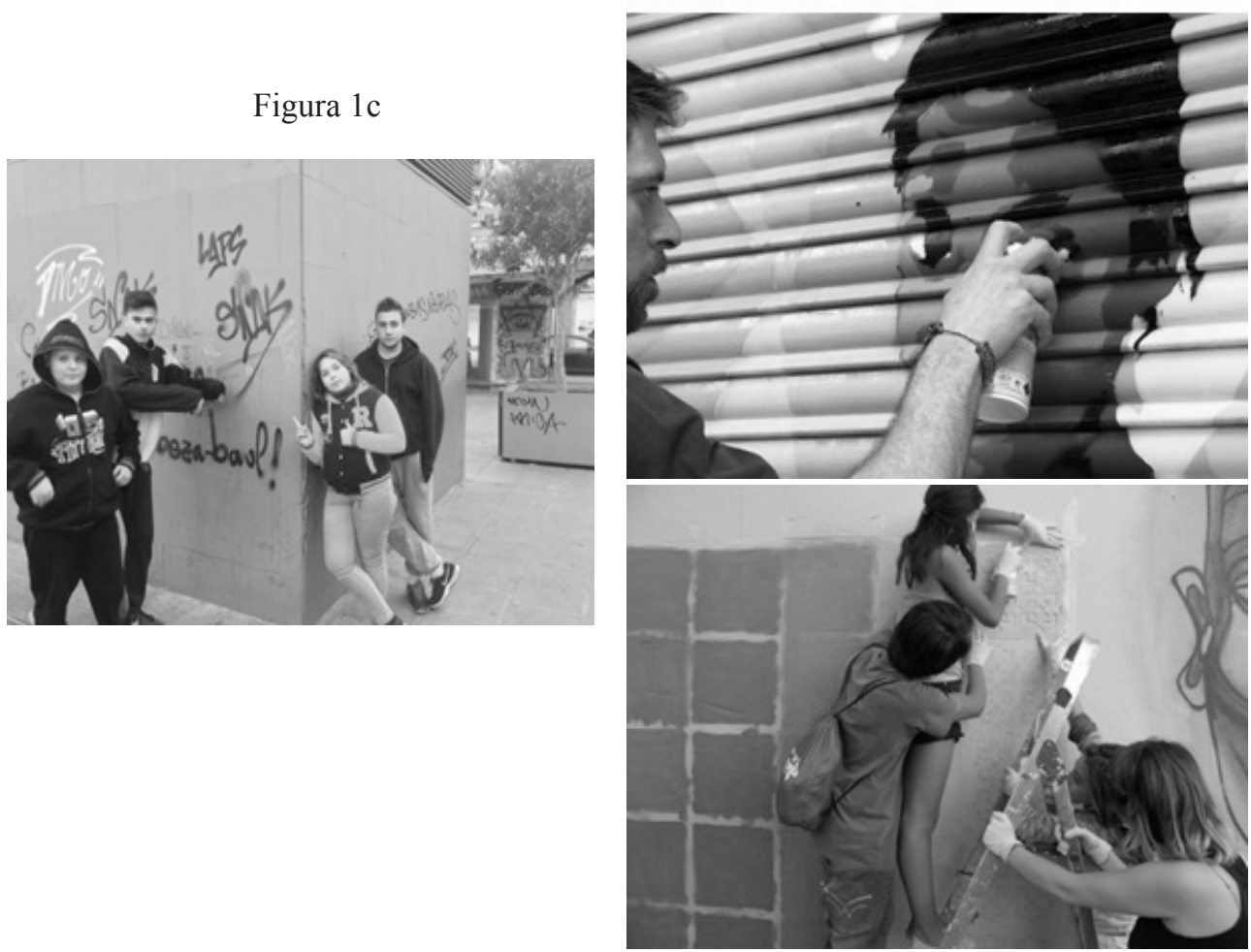

Figura 1a

Figura 1. Participación en el proceso (2016). Ensayo fotográfico compuesto por el autor con tres fotografías digitales a color de una educadora de la asociación educativa organizadora $(1 \mathrm{~b})$, un educador referente de un grupo de jóvenes (1c) y el autor (1a).

La realización de una intervención artística en el espacio público es un proceso que incluye diversas fases, como por ejemplo: identificar unas necesidades, decidir acciones para responder a éstas, identificar la ubicación específica de la intervención artística, realizar la intervención artística y difundir la intervención artística. Sin embargo, en cada caso las fases y su orden pueden ser diferentes. Por tanto, cuando se habla de acciones educativas relacionadas con el graffiti y el arte urbano hay que tomar en consideración todo lo que supone promover un proceso creativo de este tipo. En coherencia con esto, al principio, lo primero que me llamaba la atención del graffiti y arte urbano era el papel del/la artista y el resultado de la intervención artística, tal y como sucede si se mira la figura 1 de arriba abajo. No obstante, como muestran las figuras 1c y 1a, a medida que profundicé en la cuestión también identifiqué otras acciones, como por ejemplo la decisión del espacio donde realizar la intervención o el fomento de la creatividad de forma colaborativa. 
Por otro lado, si se observa la figura de izquierda a derecha se pueden identificar dos momentos diferentes: las acciones previas a la pintura y las que están estrictamente relacionadas con la pintura. En uno de los casos, en la figura 1c, las y los jóvenes participaron en la selección del espacio donde realizar la intervención artística mediante la realización de fotografías. Esta acción, que fue valorada muy positivamente por las y los jóvenes, permitió reflexionar sobre: qué uso hacen de este espacio, qué relaciones se dan alrededor de éste y cómo les gustaría intervenir artísticamente en él. Estas fotografías relacionadas con la ubicación de la intervención artística, la mayoría de las cuales fueron tomadas por los grupos de jóvenes participantes, facilitaron la incorporación de los puntos de vista de las y los jóvenes en la intervención artística.

Es bueno que se pregunte a la gente porque si vosotros decís una pared quizá la gente más del barrio no aparece tanto y no puede verla. En cambio, si es donde estamos los jóvenes y vamos siempre, en esa pared podemos decidir que está bien hacerla porque, como todo el mundo va mucho por ese lugar, podríamos verla (Conversación con Carles Radigales, joven participante en la intervención artística).

En cambio, en los casos de las figuras 1 b y 1a, las personas participaron únicamente en la pintura. Es importante poner atención en el rol del dinamizador/a en cada una. A pesar de que en ambos casos las personas participantes no pudieron opinar sobre el diseño, su participación fue cualitativamente diferente. En el caso de la 1a, las y los jóvenes participaron de forma colaborativa en la pintura. En contraposición, en el caso $1 \mathrm{~b}$, no aparecen las personas que participaron en la intervención artística, sino que se limita a mostrar el artista. A pesar de que en el caso B las y los jóvenes realizaron ciertas tareas en la pintura, escogí esta fotografía para ilustrar las opiniones de las y los jóvenes participantes:

Tú lo que no puedes pedir a unos chavales de 12, 14 y 17 años es que te hagan cuatro triangulitos de colorines. Si puedes conseguir que los chavales tengan una motivación para hacer el diseño, sí que puedes llegar a algo. Por ejemplo, yo pinté un triángulo y había un chico que decía "tú pintas aquí, tú pintas aquí...” y ya está. Veías a los chavales con las máscaras ahí... y al final era "tu pinta el triángulo y ya está" (Conversación con Daniel Velo, joven participante en la intervención artística).

A parte de factores relacionados con el planteamiento del proceso es necesario añadir los factores de carácter sistémico que condicionaron cada caso. En el caso $\mathrm{B}$, las actividades organizadas por el agente que lideró el proceso reprodujeron un sesgo en las personas participantes en términos de género y origen cultural. Por el contrario, en el caso A, hubo más diversidad durante la realización de la intervención en términos de género y origen cultural. 
La relación entre el proceso y la comunidad

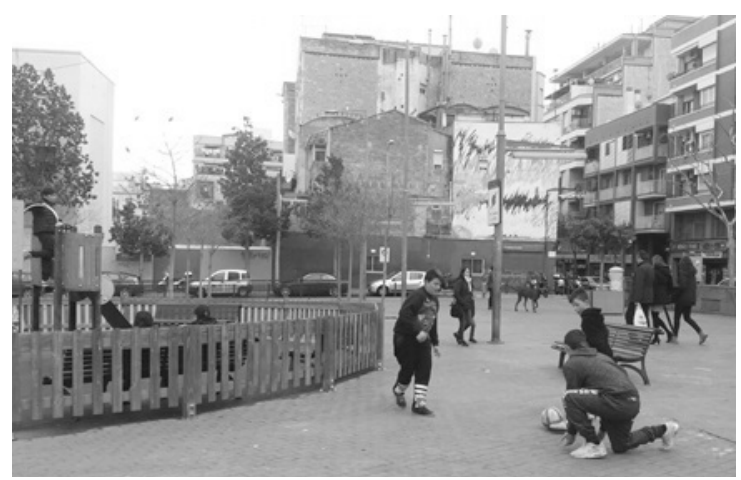

Figura 2c

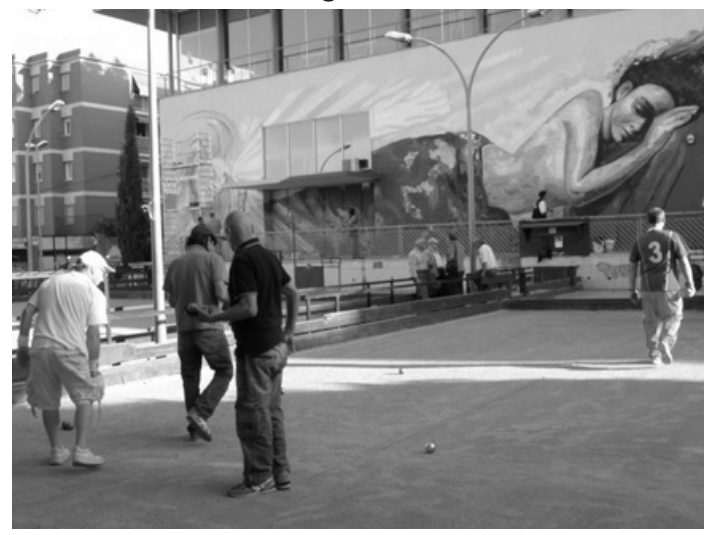

Figura 2a

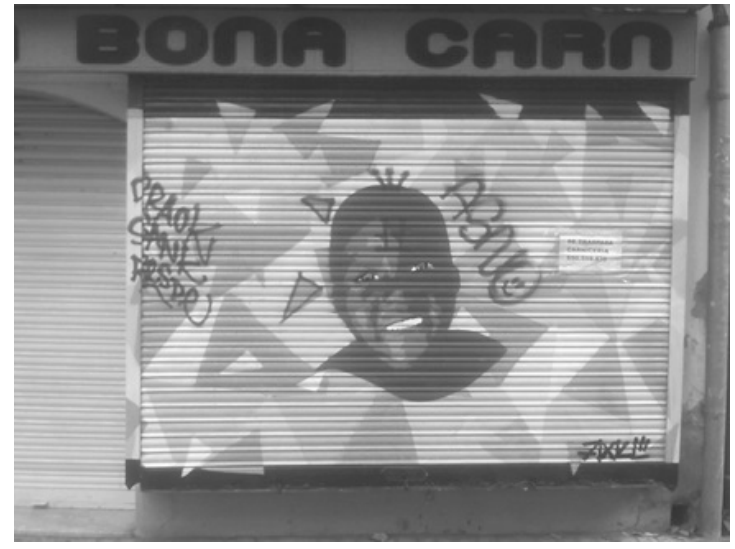

Figura $2 b$

Figura 2. ¿Proceso desde la comunidad, con la comunidad y para la comunidad? (2016). Ensayo fotográfico compuesto por el autor con tres fotografías digitales a color de una de las jóvenes participantes (2c) y el autor (2a) $y(2 b)$. 
A diferencia de los museos, donde las personas van predispuestas a contemplar las obras, las intervenciones asociadas al graffiti y arte urbano se realizan en el espacio público, habitualmente sin la autorización de las personas que las verán cada día. En consecuencia, este tipo de intervenciones artísticas se convierten en un elemento más del espacio público y pasan a ser susceptibles de nuevas interacciones con la comunidad. "Cualquier intervención (artística) no autorizada crea las condiciones para su interacción, «autorizando» el uso no autorizado de éstas" (MacDowall, 2014 en Hansen y Flynn, 2015: 31). Según estos autores, el graffiti y el arte urbano son una forma de comunicación asincrónica pero secuencial entre miembros de la subcultura del graffiti, artistas urbanos y miembros de la comunidad. Por ejemplo, el boicot a la intervención artística que organizó el equipo comunitario del barrio (ver figura $2 \mathrm{~b}$ ) constituye una reacción posterior a la pintura de las persianas por parte de jóvenes de la comunidad.

De acuerdo con lo anterior, la figura 2 aborda la relación entre el proceso y la comunidad. Compuse el ensayo fotográfico siguiendo una lógica temporal: antes de la pintura (figura 2c), durante (figura 2a) y después de ésta (figura 2b). En el primer caso (figura 2c), en el centro de la fotografía aparecen una parte de los jóvenes participantes en el proceso jugando a fútbol, que es lo que acostumbran a hacer en este espacio. En la fotografía también se pueden ver otros usos de este espacio: niños/as jugando en un parque infantil, familias paseando, personas sacando a pasear a sus perros, etc. En el fondo se observa un muro gris con un $t a g^{9}$, que fue donde las y los jóvenes realizaron su intervención artística. Por otro lado, en la fotografía siguiente (figura 2a) se puede observar qué sucedió durante la pintura alrededor de la pared donde se hizo la intervención artística. Un grupo de miembros del club de petanca aparece jugando mientras otro observa el desarrollo de un mural que está haciendo un artista en una de las fachadas del edificio. A pesar de que la organización de la actividad les invitó a participar en la pintura, los miembros del club justificaron su ausencia debido a la competición de petanca. Este ejemplo muestra que la incorporación de agentes en este tipo de procesos es una tarea compleja, pero cabe preguntarse con cuáles se promueven el trabajo en red y porqué. Esto resulta clave para entender la última fotografía (figura 2 b), posterior a la pintura. En el caso B, el equipo comunitario estableció un diálogo con las y los comerciantes para que autorizaran la realización de intervenciones artísticas en sus persianas con la finalidad de visibilizar la multiculturalidad del barrio. Para ello, encargaron a una asociación de graffiti y arte urbano local la realización de un diseño replicable a diversas persianas de una de las calles más transitadas del barrio. El trabajo positivo que condujo a conseguir diversas autorizaciones de comerciantes contrasta con las persianas boicoteadas por parte de jóvenes con sus tags y otras inscripciones, como por ejemplo «asno».

A parte de estas cuestiones, para comprender la relación del proceso y lo que sucede en el espacio público es necesario incorporar la perspectiva de género, porque las ciudades se construyeron sobre un modelo que escinde espacio público y privado en términos de género. "El espacio público se convierte en un espacio de presencia masculina frente a una intimidad femenina, ligando la capacidad de decisión y los espacios de trabajo a la masculinidad y el cuidado y los espacios interiores, a la

El término hace referencia al pseudónimo del escritor/a y a la firma realizada por parte de un miembro de las subculturas del graffiti. 
feminidad" (López, 2015: 226). Esto puede explicar que las figuras 2c y 2a estén dominadas por hombres. Sin embargo, no se trata solo de tomar en consideración aquello que se ve en las fotografías, como aquello que es invisibilizado. Esto nos conduce "hacia la necesidad de tener en cuenta determinados colectivos que quedan en los márgenes y que dan visiones contradictorias" (Rodó-de-Zárate, 2016: 14), lo cual está estrictamente relacionado con lo que sucede en el espacio privado. Otro elemento a tener en consideración es la diversidad de orígenes culturales de la población de los barrios, porque, en el caso $\mathrm{C}$, éste fue uno de los elementos clave que explicó el uso del espacio público por parte de las y los jóvenes.

\section{$\underline{\text { Las relaciones de poder existentes entre los agentes de la comunidad }}$}

Figura $3 b$

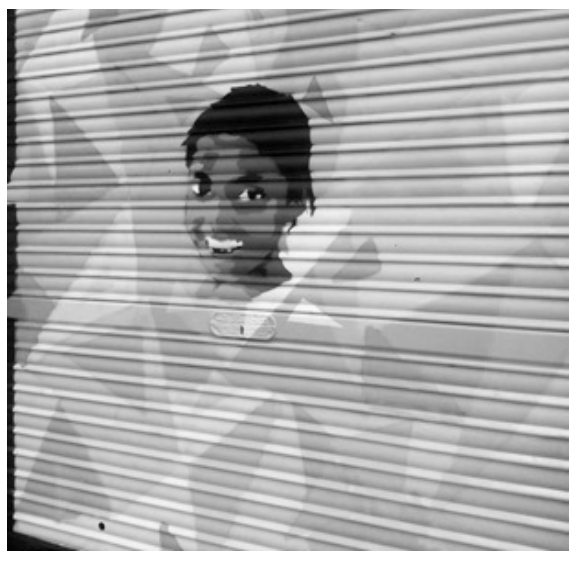

Figura 3c

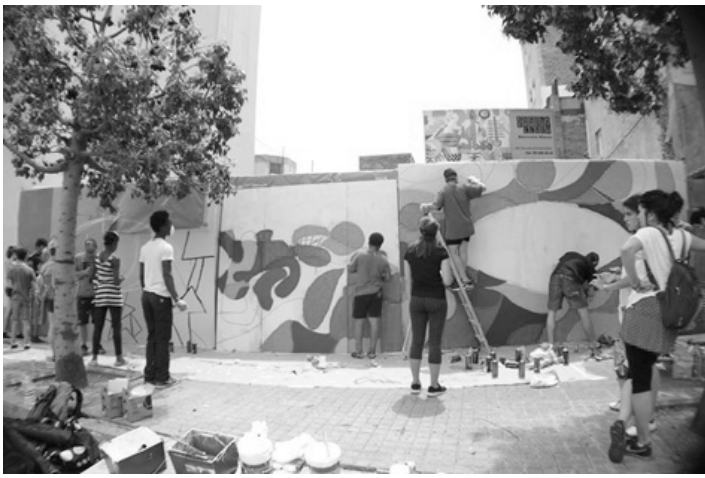

Figura 3. Poder y empoderamiento (2016). Ensayo fotográfico compuesto por el autor con dos fotografías digitales a color de una educadora de la asociación educativa organizadora (3b) y una educadora del grupo de jóvenes que participó activamente en el proceso (3c).

En los ensayos anteriores centré la atención en la participación de las y los jóvenes involucrados, la relación del proceso con la comunidad y algunos de los factores sistémicos que inciden en el proceso. El último eje de análisis tiene que ver con las relaciones de poder que existen en las comunidades. Esta cuestión se puede observar en la figura $3 b$. En el centro de la intervención realizada en la persiana de un comercio del barrio de Collblanc se observa un niño/a de una etnia africana, sonriente, sobre un fondo de triángulos de colores. Las caras que se pintaron en las persianas de los comercios aparecen sin sus respectivos cuerpos o cualquier rasgo que permitan identificar el origen cultural de las personas representadas. Visualmente, la intervención artística me sugiere que se quiso transmitir a la comunidad un mensaje «alegre», según el cual en ésta hay personas y culturas de orígenes diversos. Independientemente de la interpretación que haga cada persona, hay que reconocer que existe un mensaje detrás de esta intervención, que se realiza desde un punto de vista determinado, ya que en la comunidad habrá diferentes opiniones y vivencias en torno a la diversidad. De esto se desprenden varias cuestiones relacionadas con el 
proceso: ¿quiénes definen la narrativa de la intervención artística? ¿Cuáles son sus objetivos? ¿Qué cuestiones se han priorizado? Estos interrogantes nos conducen a las relaciones de poder que existen en la comunidad y que inciden en los procesos de educación comunitaria. Como sugiere Sánchez de Serdio (2008), la política de los proyectos colaborativos es también una política de la relación. En el caso B, el equipo comunitario que organizó el proceso fue quien definió los objetivos educativos; una asociación local de graffiti y arte urbano hizo el diseño y las y los jóvenes colaboraron en la preparación y la pintura. Así, la obra final fue fruto de un proceso colaborativo en el que las y los jóvenes tuvieron menos poder en la toma de decisiones. Paradójicamente, entre estas personas había una mayor diversidad de orígenes culturales que en el resto de agentes involucrados. Por lo tanto, las y los jóvenes y las personas de orígenes culturales no autóctonos fueron representados, pero no tuvieron voz en dicha representación.

A diferencia de la figura $3 b$, en la $3 c$ no se puede observar el resultado final de la intervención artística porque recoge uno de los momentos de la pintura. En este ensayo fotográfico no pretendo poner en valor el proceso en oposición a su resultado. El motivo principal por el cual seleccioné la fotografía $3 \mathrm{c}$ es porque se observa a jóvenes de orígenes culturales diversos pintando un mural con el apoyo de artistas de una asociación local. Las educadoras de los grupos de jóvenes se encuentran en el lateral, acompañando el proceso. En la fotografía también se pueden ver diversas de las jóvenes que se involucraron en el proceso. En el caso $\mathrm{C}$, el fondo del mural fue diseñado por las y los jóvenes con el apoyo de artistas de graffiti y arte urbano. En esta intervención artística se representaron sus sentimientos en relación a cómo viven la diversidad cultural en su día a día. Así, los agentes involucrados, incluidos los grupos de jóvenes de la asociación organizadora y otros jóvenes miembros de las subculturas del graffiti, pudieron participar en las diferentes fases del proceso. Sin embargo, la democratización del proceso del caso $\mathrm{C}$ también se vio restringida como consecuencia de las relaciones de poder existentes en la comunidad. Tal y como se apuntaba al principio, las figuras $3 \mathrm{~b}$ y $3 \mathrm{c}$ hacen referencia a procesos realizados en la misma comunidad. Con la cual cosa aquellos agentes con más poder ejercieron una influencia mayor, especialmente en los procesos de toma de decisiones de aspectos clave. A pesar de estas desigualdades, hay que apuntar que la realización de un proceso con un mayor número de agentes dificultó que unos pocos pudieran imponer sus intereses de forma unilateral.

\section{Factores que intervienen en los procesos de educación comunitaria a través de las artes mediante graffiti y arte urbano}

Un elemento característico del arte comunitario, también pertinente en el caso del graffiti y el arte urbano, es su carácter efímero. Es por este motivo que se hace tan importante documentar, analizar y visibilizar estos casos. Según López (2015), no se trata sólo de analizar la relación entre el artista y la comunidad, sino también la de todos los agentes implicados que a menudo quedan ocultos. Hay que reconocer que esta colaboración de la comunidad no se hace sin conflicto, puesto que se entiende "el disenso no como un problema a resolver sino como la misma posibilidad de existencia de la democracia” (Sánchez de Serdio, 2008: 18). Teniendo en cuenta 
esto, a continuación se presenta una tabla que recoge los factores principales que intervienen en procesos de educación comunitaria a través de las artes mediante graffiti y arte urbano. En la tabla se incluye una breve contextualización de cada caso y, además, se facilita información sobre el papel de los diferentes agentes involucrados, incluido el investigador y el papel de la cámara. La tabla no pretende tener un carácter prescriptivo, sino sintetizar la observación participante realizada y aportar más información que permitan su análisis crítico.

\begin{tabular}{|c|c|c|c|}
\hline $\begin{array}{c}\text { Categorías } \\
\text { / Casos }\end{array}$ & A & B & $\mathrm{C}$ \\
\hline $\begin{array}{l}\text { Agentes } \\
\text { involucra- } \\
\quad \text { dos }\end{array}$ & $\begin{array}{l}\text { Jóvenes, artista, aso- } \\
\text { ciación de graffiti y } \\
\text { arte urbano, espacio } \\
\text { para jóvenes }\end{array}$ & $\begin{array}{l}\text { Niños/as, jóvenes, ar- } \\
\text { tista, asociación de } \\
\text { graffiti y arte urbano, } \\
\text { espacio para jóvenes, } \\
\text { comerciantes, equipo } \\
\text { de intervención comu- } \\
\text { nitaria intercultural }\end{array}$ & $\begin{array}{l}\text { Jóvenes, miembros de } \\
\text { las subculturas del gra- } \\
\text { ffiti, artistas, asocia- } \\
\text { ción de graffiti y arte } \\
\text { urbano, espacio para } \\
\text { jóvenes, AMPA de } \\
\text { una escuela, servicios } \\
\text { municipales diversos } \\
\text { y equipos de una aso- } \\
\text { ciación educativa local }\end{array}$ \\
\hline $\begin{array}{l}\text { Agente } \\
\text { principal }\end{array}$ & $\begin{array}{l}\text { Jóvenes (mayormente } \\
\text { mujeres) }\end{array}$ & $\begin{array}{l}\text { Jóvenes (mayormente } \\
\text { hombres) }\end{array}$ & $\begin{array}{l}\text { Jóvenes (mayormente } \\
\text { hombres) }\end{array}$ \\
\hline $\begin{array}{l}\text { Recorrido } \\
\text { previo }\end{array}$ & $\begin{array}{l}\text { El agente organizador } \\
\text { no había realizado } \\
\text { ningún mural colabo- } \\
\text { rativo anteriormente }\end{array}$ & $\begin{array}{l}\text { El agente organizador } \\
\text { no había realizado } \\
\text { ningún mural colabo- } \\
\text { rativo anteriormente }\end{array}$ & $\begin{array}{l}\text { El agente organizador } \\
\text { había realizado di- } \\
\text { versas actividades de } \\
\text { carácter comunitario } \\
\text { mediante graffiti y arte } \\
\text { urbano }\end{array}$ \\
\hline $\begin{array}{l}\text { Papel del } \\
\text { artista }\end{array}$ & $\begin{array}{l}\text { Diseñar y preparar } \\
\text { el mural (mensaje, } \\
\text { composición y técni- } \\
\text { ca) para que todas las } \\
\text { personas puedan par- } \\
\text { ticipar independiente- } \\
\text { mente de su conoci- } \\
\text { miento técnico }\end{array}$ & $\begin{array}{l}\text { Diseñar el mural } \\
\text { (composición) y otor- } \\
\text { gar tareas específicas } \\
\text { a las personas partici- } \\
\text { pantes, también en las } \\
\text { actividades preparato- } \\
\text { rias }\end{array}$ & $\begin{array}{l}\text { Hacer sesiones de for- } \\
\text { mación técnica, orien- } \\
\text { tar el diseño (mensaje, } \\
\text { composición y técnica) } \\
\text { con las personas par- } \\
\text { ticipantes y acompa- } \\
\text { ñar el proceso. En la } \\
\text { realización, colaborar } \\
\text { en las tareas que re- } \\
\text { quieren más dominio } \\
\text { técnico }\end{array}$ \\
\hline $\begin{array}{l}\text { Papel del } \\
\text { agente } \\
\text { principal }\end{array}$ & $\begin{array}{l}\text { Participar en la pintura } \\
\text { de la intervención ar- } \\
\text { tística }\end{array}$ & $\begin{array}{l}\text { Participar en la prepa- } \\
\text { ración y realización de } \\
\text { la intervención artísti- } \\
\text { ca }\end{array}$ & $\begin{array}{l}\text { Participar en la toma } \\
\text { de decisión de cuestio- } \\
\text { nes fundamentales de } \\
\text { la intervención artís- } \\
\text { tica, su preparación y } \\
\text { realización }\end{array}$ \\
\hline
\end{tabular}




\begin{tabular}{|c|c|c|c|}
\hline $\begin{array}{l}\text { Papel del } \\
\text { resto de } \\
\text { agentes* }\end{array}$ & $\begin{array}{l}\text { I) Autorizar la realiza- } \\
\text { ción de la intervención } \\
\text { artística en el muro de } \\
\text { su edificio; } \\
\text { II) difundir la acción } \\
\text { educativa }\end{array}$ & $\begin{array}{l}\text { I) Establecer un diá- } \\
\text { logo con comercian- } \\
\text { tes para conseguir las } \\
\text { autorizaciones para la } \\
\text { realización de la in- } \\
\text { tervención artística; } \\
\text { II) difundir la acción } \\
\text { educativa }\end{array}$ & $\begin{array}{l}\text { I) Debatir las acciones } \\
\text { educativas; II) incluir } \\
\text { las acciones previstas } \\
\text { en sus líneas de traba- } \\
\text { jo; } \\
\text { III) dinamizar alguna } \\
\text { de las acciones; IV) } \\
\text { participar en la toma } \\
\text { de decisiones; V) di- } \\
\text { fundir el proceso rea- } \\
\text { lizado; VI) conseguir } \\
\text { autorización para la } \\
\text { realización de la inter- } \\
\text { vención artística }\end{array}$ \\
\hline $\begin{array}{l}\text { Papel que } \\
\text { tiene el in- } \\
\text { vestigador }\end{array}$ & $\begin{array}{l}\text { Observación no parti- } \\
\text { cipante }\end{array}$ & Evaluación posterior & $\begin{array}{l}\text { Fomento de la partici- } \\
\text { pación, facilitador en- } \\
\text { tre agentes y dinami- } \\
\text { zador en determinadas } \\
\text { ocasiones }\end{array}$ \\
\hline $\begin{array}{l}\text { Papel de la } \\
\text { cámara }\end{array}$ & $\begin{array}{l}\text { Documentar externa- } \\
\text { mente la realización } \\
\text { de la intervención ar- } \\
\text { tística }\end{array}$ & $\begin{array}{l}\text { Documentar los cam- } \\
\text { bios visuales que ha } \\
\text { sufrido la intervención } \\
\text { artística }\end{array}$ & $\begin{array}{l}\text { I) Identificar los espa- } \\
\text { cios significativos del } \\
\text { barrio; II) reflexio- } \\
\text { nar sobre qué sucede } \\
\text { en éstos; } \\
\text { III) compartir los ins- } \\
\text { trumentos de investi- } \\
\text { gación con las y los jó- } \\
\text { venes; IV) documentar } \\
\text { el proceso; V) difun- } \\
\text { dirlo }\end{array}$ \\
\hline
\end{tabular}

Tabla 1. Resumen de los procesos analizados.

*Acciones realizadas por alguno de los agentes involucrados, no todos ellos.

\section{Reflexiones finales}

El análisis de los datos recogidos muestra que los procesos de educación comunitaria a través de las artes mediante graffiti y arte urbano constituyen formas de creatividad para la conformación de espacios de encuentro comunitario. Los casos analizados van desde la participación puntual en acciones colaborativas, el establecimiento o fortalecimiento de vínculos entre agentes, hasta la realización de diversas acciones creativas alrededor de espacios significativos para las y los jóvenes. A pesar de esto, sería simplista hacer estas afirmaciones sin reconocer la complejidad existente en este tipo de procesos.

En los todos los casos analizados (ver tabla 1) hay una colaboración entre un agente educativo y otro cultural que organizan diversas acciones educativas donde las y los jóvenes son los protagonistas. Sin embargo, en algunos casos hay otros 
agentes que también colaboran de alguna manera: jóvenes de las subculturas del graffiti, comerciantes, AMPAs o servicios municipales diversos. El papel de las y los jóvenes consiste en realizar la intervención artística, pero también puede implicar la participación en acciones preparatorias o en la toma decisiones de cuestiones clave de cada proceso. Esto está relacionado con el papel que adopta el/la artista en cada caso: fomentando la participación mediante tareas específicas, promoviendo la implicación mediante la asignación de tareas compartidas o adoptando una posición de acompañamiento durante el proceso. Además, es importante tomar en consideración el papel de la comunidad. Mientras que en algún caso ésta se limita a autorizar la intervención artística, en otros se inician procesos de diálogo que acaban en la suma compartida de objetivos educativos mediante el trabajo en red.

Sin embargo, los ensayos visuales muestran diversas limitaciones. En primer lugar, relacionadas con la participación de las personas involucradas. Por este motivo en algunos casos las y los jóvenes reclaman tener más voz. Además, de este análisis se desprenden limitaciones en relación a la diversidad de las personas participantes, en términos de género y origen cultural. Por otro lado, también hay que considerar las limitaciones asociadas a la relación proceso-comunidad: los agentes que se invitan en cada proceso, la relación que se establece con cada uno y cómo se fomenta el trabajo en red. Asimismo, hay que poner de manifiesto las relaciones de poder existentes entre los agentes involucrados, ya que inciden en los diversos aspectos de cada uno de los casos analizados (objetivos, elementos que se han priorizado durante el proceso, la narrativa de la intervención artística, etc.). No obstante, los análisis realizados no son suficientes para comprender estas limitaciones en su globalidad, lo cual hace necesario seguir profundizando en estas cuestiones.

Ante el auge de procesos de colaboración mediante graffiti y arte urbano, es importante su documentación y análisis crítico para evitar la instrumentalización de la participación de las comunidades. La posición que he adoptado en el análisis me lleva a considerar que si hoy en día se quieren fomentar acciones educativas de este tipo hay que plantear estos procesos desde la complejidad y considerar los factores sistémicos que afectan la participación de la comunidad, como por ejemplo el género y el origen cultural. Por último, es importante no considerar las comunidades desde visiones idealizadas y poner de manifiesto la diversidad de agentes, necesidades e intereses.

\section{Referencias bibliográficas}

Abarca, J. (2010) El postgraffiti, su escenario y sus raices: Graffiti, punk, skate y contrapublicidad (Tesi doctoral no publicada). Madrid, Universidad Complutense de Madrid.

Adeline, J. (2015) "Street Girls: The rise of female street art". En: http://www.catfightmagazine.com/modart_article.pdf

Avramidis, K. y Dakopoulou, K. (2012) « Graffiti Crews' Potential Pedagogical Role». En Journal for Critical Education Policy Studies, 10, 1, pp. 327-340.

Biglia, B. (2007) "Desde la investigación-acción hacia la investigación activista feminista".

En J. Romay (Coord.), Perspectivas y retrospectivas de la psicología social en los albores del siglo XXI (pp. 415-422). Madrid, Biblioteca nueva.

y Zavos, A. (2005) "Situar-nos a dins, a fora o a la frontera: Quines (im)possibles relacions 
entre l'activisme i l'acadèmia en les 'investigacions crítiques'”. En E. Alfama, I. Azueta, M. Balasch, C. Barker, M. Bergel, B. Biglia, ... M. Fuster y Morell, Recerca i activista i moviments socials (pp. 83-90). Mataró, Ediciones de Intervención Cultural y El Viejo Topo.

Calogirou, C. (2010) “Moviments artístics urbans contestataris: El graffiti”. En Revista d'Etnologia de Catalunya, 6, pp. 28-39.

Castells, M. (1977) The urban question: a Marxist approach. Londres, Edward Arnold.

Civís, M. y Riera, J. (2007) Nueva pedagogía comunitaria: Un marco renovado para la acción. Barcelona, Nau Llibres.

Civís, M. y Longás, J. (2015) "La colaboración interinstitucional como respuesta al desafío de la inclusión socioeducativa: Análisis de 4 experiencias de trabajo en red a nivel local en Cataluña". En Educación XX1, 18, 1, pp. 213-236.

Connnell, R. W. y Messerschmidt, J. W. (2005) "Hegemonic Masculinity: Rethinking the Concept". En Gender Society, 19, pp. 829-859.

Hansen, S. y Flynn, D. (2015) "Longitudinal photo-documentation: Recording living walls". En Street Art \& Urban Creativity Scientific Journal, 1, 1, pp. 26-31.

Harvey, D. (1973) Social justice and the city. Londres, Edward Arnold.

Latorre, G. (2008) Walls of empowerment: Chicana/o Indigenist Murals of California. Austin, University of Texas Press.

Lefebvre, H. (1969) El derecho a la ciudad. Barcelona, Península.

López, M. (2015) "Indicadores sobre prácticas artísticas comunitarias: algunas reflexiones". En Arteterapia: Papeles de arteterapia y educación artística para la inclusión social, 10, pp. 209-234.

MacDonald, N. (2001) The grafffiti subculture: Youth, masculinity and identity in London and New York. Houndmills, Palgrave MacMillan.

Marcellán-Barace,I., Lander, C., Aguirre, I. y Arriaga, A. (2013) "Estudio sobre jóvenes productores de cultura visual: evidencias de la brecha entre la escuela y la juventud". En Arte, Individuo y Sociedad, 25, 3, pp. 524-535.

Marín, R. y Roldán, J. (2010) "Photo essays and photographs in visual arts-based educational research". En International Journal of Education through Art, 6, 1, pp. 7-23.

Mayugo, C., Pérez, X. y Ricart, M. (2004) Joves, Creació i Comunitat. Barcelona, Fundació Jaume Bofill.

Mcauliffe, C. (2012) "Graffiti or Street Art? Negotiating the moral geographies of the creative city". En Journal of Urban Affairs, 34, 2, pp. 189-206.

(2013) "Legal Walls and Professional Paths: The Mobilities of Graffiti Writers in Sydney". En Urban Studies, 50, 3, pp. 518-537.

Mcniff, J. (1988) Action research: principles and practice. Houndmills, MacMillan Education.

Novak, D. (2015) "Photography and Classification of Information: Proposed Framework for Graffiti Art”. En Street Art \& Urban Creativity Scientifc Journal, 1, 1, pp. 13-25.

Palacios, A. (2009) "El arte comunitario: origen evolución de las prácticas artísticas colaborativas". En Arteterapia: Papeles de arteterapia y educación artística para la inclusión social, 4, pp. 197-211.

Pink, S. (2006) The Future of Visual Anthropology: Engaging the senses. Nueva York, Routledge.

(2011) "Images, Senses and Applications: Engaging Visual Anthropology". En Visual Anthropology: Published in cooperation with the Comission on Visual Anthropology, 24, 5, pp. 437-454. 
(2014) "Digital-visual-sensory design anthropology: Ethnography, imagination and intervention”. En Arts \& Humanities in Higher Education, 13, 4, pp. 412-427.

Recinos, E. (2015) “Is Street Art Sexist?” En: http://www.artslant.com/9/articles/show/41661

Rodó-de-Zárate, M. (2013) “Gènere, cos i sexualitat: La joventut, l'experiència i l'ús de l'espai públic urbà'. En Papers, 98, 1, pp. 127-142.

(2016) “¿Quién tiene derecho a la ciudad? Jóvenes lesbianas en Brasil y Cataluña desde las geografías emocionales e interseccionales". En Revista Latino-americana de Geografia e Gênero, 7, 1, pp. 3-20.

Sánchez de Serdio, A. (2008) "Prácticas artísticas colaborativas: el artista y sus socios invisibles". En DHuarte, 3, pp. 17-18.

Torres, A. (2002) "Reconstruyendo el vínculo social: lo comunitario en tiempos globalizados". En Revista Prospectiva, 6-7, pp. 27-44. En: http://bibliotecadigital.univalle.edu.co/ bitstream/10893/1165/1/Prospectiva\%206\%20y\%207.p.27-44\%2c2002.pdf

Waclawek, A. (2011) Graffiti and Street Art. Londres, Thames \& Hudson Ltd. 